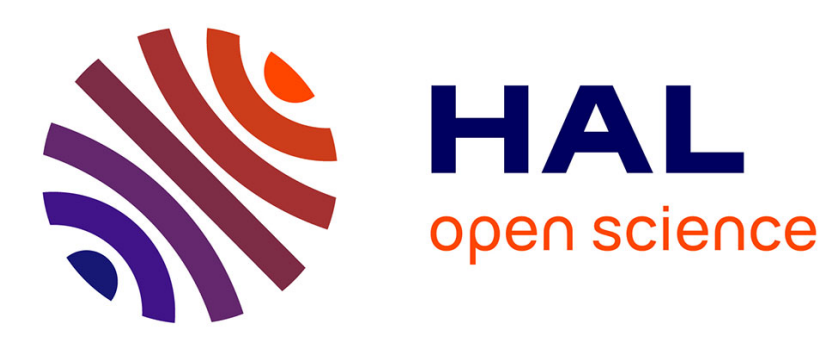

\title{
Olfactory detection of trace amounts of plant volatiles is correlated with testosterone in a passerine bird
} Jessica L. Graham, Thierry D Charlier, Francesco Bonadonna, Samuel Caro

\section{To cite this version:}

Jessica L. Graham, Thierry D Charlier, Francesco Bonadonna, Samuel Caro. Olfactory detection of trace amounts of plant volatiles is correlated with testosterone in a passerine bird. Hormones and Behavior, 2021, 136, pp.105045. 10.1016/j.yhbeh.2021.105045 . hal-03330902

\section{HAL Id: hal-03330902 https://hal.science/hal-03330902}

Submitted on 1 Sep 2021

HAL is a multi-disciplinary open access archive for the deposit and dissemination of scientific research documents, whether they are published or not. The documents may come from teaching and research institutions in France or abroad, or from public or private research centers.
L'archive ouverte pluridisciplinaire HAL, est destinée au dépôt et à la diffusion de documents scientifiques de niveau recherche, publiés ou non, émanant des établissements d'enseignement et de recherche français ou étrangers, des laboratoires publics ou privés. 
1 Olfactory detection of trace amounts of plant volatiles is correlated with testosterone in a 2 passerine bird

3

4 Jessica L. Graham ${ }^{1, \dagger}$, Thierry D. Charlier ${ }^{2}$, Francesco Bonadonna ${ }^{1}$, Samuel P. Caro ${ }^{1, *}$

5

$6 \quad{ }^{*}$ Corresponding author: Samuel.caro@cefe.cnrs.fr; 33.(0)4.67.61.33.08 (P)

$7 \quad{ }^{1}$ CEFE, Univ Montpellier, CNRS, EPHE, IRD, Univ Paul Valéry Montpellier 3, Montpellier,

8 France

9 Email: Francesco.bonadonna@cefe.cnrs.fr

10 'Univ Rennes, Inserm, EHESP, Irset (Institut de Recherche en Santé, Environnement et

11 Travail), UMR_S 1085, F-35000 Rennes, France

12 Email: Thierry.charlier@univ-rennes1.fr

13 tCurrent Address: Department of Biological Sciences, North Dakota State University, Fargo, ND 1458102, USA

15 Email: Jessica.I.graham@ndsu.edu 


\section{Abstract}

17 In response to damage by insects, plants release herbivore-induced plant volatiles (HIPVs) into 18 the air. Insectivorous birds exploit these cues and, consequently, reduce the damages inflicted to 19 the plants. However, little is known about whether they solely use HIPVs as foraging cues, or if 20 they also use them to modulate traits linked to reproduction. As caterpillars are the primary food 21 source required for insectivorous birds to raise offspring, their ability to locate and predict future 22 peaks in caterpillar biomass using olfaction is likely to be advantageous. Therefore, we tested 23 whether an insectivorous songbird that naturally inhabits oak dominated forests can be trained to 24 detect early spring infestation by hatchling caterpillars, at a time when oaks begin bursting, and birds prepare to breed. Tree buds were either infested with caterpillars or left as a control and 26 visually obscured in a Y-Maze choice test. Additionally, we measured testosterone and $17 \beta$ 27 estradiol as they influence olfactory perception in mammals and are linked to reproduction in vertebrates. After being trained to associate the presence of HIPVs with that of food, blue tits spent more time with, were more active around, and more frequently chose to first visit the infested trees, showing that blue tits can smell caterpillar activity. Males with higher testosterone spent more time around infested trees, suggesting that foraging behavior during the pre-breeding season is linked with a major reproductive signal. There was no relationship between foraging and estradiol in females. These results are an important foundation for further investigation of the role of hormones in avian olfaction and how smell may be useful for making breeding decisions that could improve reproductive success.

36 Keywords: seasonal reproduction, olfaction, alarm HIPVs, testosterone, estradiol 


\section{Introduction}

Plants often emit chemical cues that protect them from damage caused by herbivores. In the case of herbivorous insects, volatile alarm signals released into the air attract carnivorous arthropods that protect the plants from damage (Turlings and Benrey, 1998; Van Poecke et al., 2001) by significantly reducing the number of herbivorous insects present on the plant (Kessler and Baldwin, 2001). In addition, some carnivorous arthropods appear to exploit these olfactory cues to prepare for reproduction. For example, ladybird beetles (Harmonia axyridis and Oenopia conglobata) experiencing a prey shortage will invest more in reproduction when presented with olfactory cues from aphid-infested plants (Rondoni et al., 2017). While most work on the influence of plant signals on animal behavior and physiology has focused on insects (Turlings and Benrey, 1998; Van Poecke et al., 2001), less is known about the abilities of vertebrates to detect and exploit these plant cues (Mrazova et al., 2019).

The olfactory ability of birds has become a popular area of study over the past few decades. Research has shown birds are capable of using smell in recognition of individuals (Bonadonna and Nevitt, 2004; Bonadonna and Sanz-Aguilar, 2012; Krause et al., 2012; Whittaker et al., 2011), selecting nest building materials (Clark and Mason, 1987; Petit et al., 2002), navigation (Bonadonna and Gagliardo, 2021; Gagliardo et al., 2013), and even modifying behavior to avoid predators (Amo et al., 2008; Roth II et al., 2008). There is growing evidence that insectivorous birds can also use their sense of smell in a foraging context, to detect infestation of plants by herbivorous insects (Amo et al., 2013; Mennerat et al., 2005). For example, the experimental infestation of birch trees (Betula pubescens) increases avian predation rates (Mäntylä et al., 2008). Similarly, birds are attracted to branches from infested pine trees (Pinus sylvestris) more than branches from uninfested trees (Mäntylä et al., 2017). However, in both these studies birds were able to see the infested trees and infestation can cause visual changes to trees (Amo et al., 2013). To our knowledge, only one published study exclusively tested the olfactory ability of birds to detect infested plants (Amo et al., 2013). 
Among insects, caterpillars are particularly important for insectivorous birds, as they represent the primary food source required to successfully raise offspring (Naef-Daenzer and Keller, 1999). Thus, it may be expected that terrestrial birds may also use odors associated with food to detect it (Amo et al., 2013) and thereby constitute one of the most important selection factors in those bird species (Blondel et al., 1999). One such odor potentially associated with future food availability during the breeding season is herbivore-induced plant volatiles (HIPVs) released by plants in response to caterpillar herbivory. Volatile signals of caterpillar presence could modulate various behavioral and physiological processes in birds. If insectivorous birds like great tits use alarm signals from plants to forage for themselves and for feeding their chicks at a time when caterpillar biomass is large (i.e., late instar stages) and tree leaves are fully developed (Amo et al, 2013), birds may also use alarm signals from plants earlier in the season, when caterpillar biomass is still low because they just hatched and are even too small to be considered food. However, the olfactory detection of plants infested with young caterpillars has never been studied.

It has previously been shown that when young leaves are infested, monoterpene emissions are produced, but in significantly smaller amounts compared to mature leaves (Brilli et al., 2009). Cotton buds infested with Helicoverpa zea (Röse and Tumlinson, 2004) and oak buds infested with first instar green oak tortrix (Tortrix viridana) and winter moth (Operophtera brumata) caterpillars (about $1 \mathrm{~mm}$ long) (Graham et al. unpublished results) already emit alarm volatile compounds, but in minute amounts compared to fully developed leaves. At this early stage, caterpillars live as miners in the buds, and are therefore invisible to potential predators (Du Merle and Mazet, 1983). Detecting such minute amounts of volatile signals could be challenging for birds, but there could nevertheless be several potential benefits to be gained from using such early signals of caterpillar presence in the environment. Birds might, for example, use the timing and intensity of the odorous signal to assess the quality of territories (Girling et al., 2011; Nyström, 1997). They could also use those signals to adjust clutch size in preparation for high or low insect 
89 abundance (Gols et al., 2003; Hussell and Quinney, 1987; Marciniak et al., 2007), or potentially 90 even to adjust laying date in response to year-to-year variation in the date of emergence of caterpillars. In order to determine if birds do make use of these early signals, we must first determine whether birds are capable of detecting the trace amounts of HIPVs emitted from developing buds, independently of visual cues. This is the main purpose of the present study.

If birds are detecting trace amounts of plant HIPVs and using those cues to make breeding decisions, any modification of reproductive behavior is likely to be primed by reproductive hormones (Ball and Balthazart, 2009, 2004; Wingfield et al., 1987). The relationship between chemosignals and their influence on the reproductive system is well documented in mammals, fish, and amphibians (Kawai et al., 2009; Nikonov et al., 2017; Petrulis, 2013), but less is known in birds (Caro and Balthazart, 2010), let alone for olfactory signals other than bodily odors, like plant or food odors for example. Work in several avian species suggest sex-steroids, like testosterone, stimulate more persistent food searching behavior (Andrew, 1972; Daisley et al., 2005; Németh et al., 2015), which is likely to be beneficial in early spring for acquiring resources for successful reproduction (e.g., territory, mate, food) (Lack, 1968; Wingfield, 1984). Additionally, olfactory sensitivity in rats appears to be upregulated by local sex-steroid production in the olfactory epithelium (Horie et al., 2017; Lupo et al., 1986), though whether this is the case in birds is unknown. Alternatively, it may be the exposure to some relevant odor signals that regulates sex-steroid dynamics, similarly to the stimulatory effect of pheromones on sex-steroid hormones (Miller and Maner, 2010). In any case, the relationship between behavior in response to an odor associated with food and pre-breeding reproductive hormones has not been studied.

The purpose of this study was to determine if insectivorous songbirds can detect the emissions of caterpillar infested trees early in the spring by smell only, and whether this is linked to their endocrine status. As blue tits (Cyanistes caeruleus) primarily inhabit oak dominated forests, we infested young oak trees with two common species of freshly hatched caterpillars that, later in the season, represent a major part of their natural diet in temperate zones: winter moths 
115 (Operophtera brumata) and green oak tortrix (Tortrix viridana). We hypothesized that after 116 training, birds would be able to differentiate between infested and uninfested oak trees by smell 117 during the early stages of bud development, and that individuals that are more reproductively 118 ready would spend more time near the infestation.

Blue tits were trapped and maintained under licenses 2015615-147 issued by the Direction 123 Régionale de l'Environnement, de l'Aménagement et du Logement Languedoc-Rousillon; and 15124 XIX-116 issued by the Direction Départementale de la Protection des Populations de l'Hérault. 125 Experiments were run under the license 2017-XIX-075 from the Direction Départementale de la 126 Protection des Populations de l'Hérault, and approved by the Ethical committee $\mathrm{N}^{\circ} 036$ with 127 reference APAFIS\#8608-2017012011062214 v4.

Housing of blue tits (Cyanistes caeruleus)

CNRS) in Montpellier, France $\left(43^{\circ} 37^{\prime} 56^{\prime \prime} \mathrm{N}, 3^{\circ} 52^{\prime} \mathrm{E}\right)$ from 15 April to 2 May 2018 . We used 42 132 hand-raised blue tits (females: $n=20$, males: $n=22$ ). Birds were moved indoors between 28 133 February and 14 March 2018 and were housed individually in cages $(0.8 \times 0.4 \times 0.35 \mathrm{~m})$. Males and females were housed in separate rooms and females were never observed laying eggs for the duration of the study. Individuals were provided water and food ad libitum. Food consisted in a cake made of sunflower seed grease, eggs, sugar, wheat flour and high-protein pellets (Show $1371+2$ crumble, Versele-Laga, Deinze, Belgium), supplemented with minerals, vitamins, amino138 acids and carotenoids (Nutribird A21, Versele-Laga, Deinze, Belgium; Nekton-S, Günter Enderle, 139 Pforzheim, Germany; Yel-Lux, Versele-Laga, Deinze, Belgium). Mealworms were provided 3 140 times per week. Windows in the rooms allowed natural light to filter in while light timers were set 
141 to turn on high-frequency TL tubes (Phillips TL5 HO 90 De Luxe 49W 965, Phillips, Eindhoven, 142 The Netherlands) 15 minutes post-sunrise and turn off 15 minutes prior to sunset, providing 143 natural increases and decreases in light intensity to occur (Fleissner and Fleissner, 2002). Sunrise 144 and sunset times were determined using the United States Naval Observatory data base 145 (www.usno.navy.mil/USNO). When moved, birds' feathers were checked to confirm they were in 146 good condition, so flight capability was not inhibited.

\section{Oak Trees}

149 In the spring of 2018, 80 downy oak trees (Quercus pubescens Willd.; approx. $2 \mathrm{~m}$ high, 150 and $0.8 \mathrm{~m}$ of diameter) grown in pots were maintained on the north side of a building $(n=20)$, 151 south side of a building $(n=20)$, or at a higher elevation to delay bud burst $(n=40)$. All trees were 152 treated with copper in a Bordeaux mixture (AMM 9500302) and a rapeseed oil insecticide 153 (Naturen Eradibug, AMM 2110150) in the winter preceding each experiment to reduce the chance 154 any fungus and wild insects infested the trees and caused other HIPV emissions than the ones 155 induced by our caterpillar infestation. Once the oak buds began to elongate and lose their scales, 156 they were considered ready to use in the experiment as caterpillars are unable to perforate the 157 protective scales to enter the bud prior to this stage of development (Du Merle and Mazet, 1983). 158 Of the 80 total trees, 24 were used in this experiment and 33 were used in a separate study 159 specifically measuring HIPV production of oak buds experimentally infested with the same 160 caterpillar species as here (Graham et al. unpublished results).

\section{Caterpillars and bud infestation}

We utilized 2 species of caterpillars for this project: winter moth (Operophtera brumata) 164 and green oak tortrix (Tortrix viridana). Eggs of green oak tortrix were collected from tree branches the previous summer from Corsica, France while winter moth eggs were collected in the lab on 
166 paper strips in The Netherlands. Eggs were kept in an unheated building overwinter and moved 167 outdoors in spring so caterpillars and trees were experiencing the same weather conditions.

168 Once caterpillars began to hatch, oak trees with buds at an appropriate stage were either 169 infested with caterpillars (using a small paintbrush to gently place caterpillars on the bud) or left 170 as a control, $72 \mathrm{hrs}$ prior to being used in a Y-maze (table 1). We chose $72 \mathrm{hrs}$ post-infestation 171 because data collected from experimentally infested oak buds found HIPVs significantly increase $17248-72$ hrs post-infestation when compared to uninfested, control buds (Graham et al. 173 unpublished data). A single oak tree was placed at the end of each active arm (4 arms total, see 174 below), so only 4 trees were used at one time. To infest a tree, 20 caterpillars were placed across 1755 branches with stage 4 (bud elongated, swollen and green) - 6 (bud bursting, leaf shoots can be 176 distinguished but are still intricated) buds (Du Merle and Mazet, 1983). T. viridana were given 177 priority as they are native to the area, however, when not enough were available, O. brumata 178 were used to keep the number of caterpillars on infested trees consistent. We recently found there 179 is no difference in the volatile compounds emitted by oak buds when they were infested by either 180 one of these two caterpillar species (Graham et al, unpublished results). A small wire cage was 181 placed around the infested bud(s) and covered by a mesh bag to ensure caterpillars remained on 182 the bud. The cage kept the bag from coming into contact with the bud(s), to prevent alarm 183 emission due to mechanical stress (Kesselmeier and Staudt, 1999). Mean individual caterpillar 184 mass for this study was $7.799 \pm 0.990 \mathrm{mg}$. Control trees remained uninfested but had cages and 185 bags on 5 branches to control for any emissions the tree may have produced in response to the 186 presence of the cages. An individual bird was never exposed to the same pair of trees more than 187 once and trees used on the day of the experiment had never been used during any of the training 188 (see below). 


\section{Y-Mazes}

Two large outdoor y-mazes $(2.5 \times 2 \mathrm{~m}$ arms, figure $\mathrm{S} 1)$ were set up facing southeast. Two arms were designated as active arms (one control and one treatment arm) and a neutral arm containing no stimuli where the bird entered the maze. Each active arm of the maze had five food dishes and one perch, and one additional perch was placed in the neutral arm of the maze. Food dishes were the same as those used to feed birds when housed in outdoor aviaries, so they were already familiar to the birds. A small box was mounted on the door in the neutral arm to introduce birds into the maze. Mazes were visually isolated from each other by a hedge. A wind break was set up around the maze that additionally reduced visibility beyond the arms of the maze. Stands placed at the far end of the two active arms of the maze (outside the maze, against the mesh) contained the trees. Those stands were covered with a white fabric on three sides (those visible from the inside of the maze) to block any changes in color infested trees may display compared to uninfested trees (Amo et al., 2013). These enclosures also had small fans $(92 \times 92 \times 25 \mathrm{~mm}$, $36 \mathrm{~m}^{3} / \mathrm{h}$, EbmPapst, Chelmsford, UK) to blow air from the trees toward the center of the maze (placed at $80 \mathrm{~cm}, 130 \mathrm{~cm}$, and $180 \mathrm{~cm}$ from the ground). Behavioral observations always started as soon as a bird left the entrance box. Habituation, training, and testing began as early as 08:40 and were completed by 16:45 each day (For full experimental design, see table 1). A water bath was also available in each arm of the maze, so the birds always had access to fresh water.

\section{Habituation}

We were unable to observe 42 birds in a day, so we ran the experiment twice. Group 1 consisted of 20 birds (10 males, 10 females) sampled from 15 April to 21 April 2018. Group 2 consisted of 22 birds (12 males, 10 females) sampled from 26 April to 2 May 2018. To habituate birds to the mazes, flocks of $3-4$ birds were released into the maze for a minimum of 2 hours. Food was removed from the birds' housing cages 60 - 90 minutes before a bird was introduced to the maze, to stimulate food searching. A mixture of food rewards (cake, mealworms) were 
216 placed in all 10 dishes at the end of both arms of the maze to encourage exploration. No trees or 217 caterpillars were used during habituation. However, the empty tree enclosures and fans were in 218 place so birds could habituate to their visual and auditory presence.

220 Training 30 min with 1 food item placed in each dish only in the side of the maze containing an infested tree (Amo et al., 2013). Empty food dishes remained in the side of the maze with the control tree.

224 The type of food reward was changed each day to keep birds from learning the scent of the food reward instead of the oak emissions (see table 1). The quantity of the food reward was recorded so we could keep track of whether birds were consuming the reward, and therefore whether they had a chance to associate the presence of oak emission with food. Additionally, the birds experienced the infested tree approximately equally on each side of the maze over the successive training sessions, so they would not become familiar with finding food on one side of the maze. Due to an odd number of trainings, half of the birds experienced the infested tree and food reward three times on the right side of the maze, while the other half of the birds experienced the infested tree and food reward three times on the left side of the maze. The side the infested tree was on was alternated between the left and right side daily for every individual. Order of individuals was randomly assigned, but one male and one female were always being tested in parallel in the two mazes with the exception of 2 males being tested at the same time during the second round of 236 the experiment.

During the first training session, we observed that birds were less motivated to search for the food reward in the afternoon compared to the morning. To overcome this potential confounder, we alternated birds from the second group between morning and afternoon training sessions, so every bird experienced the maze $2-3$ times in the morning. This reduced the number of birds 241 that did not find the reward in at least half of the trainings from $40.0 \%$ of birds in the first round to 
$24222.7 \%$ in the second round. In addition, inclement weather during the second round of trainings 243 resulted in 12 birds only undergoing 4 rounds of training as opposed to 5 rounds.

Trials were performed once per individual and conducted in similar way to the training. A

\section{Behavioral Observations}

Behavior was recorded by an observer blind to the treatment, using the free event logging software: Behavioral Observation Research Interactive Software (BORIS version 6.3.5, Friard and Gamba 2016). Videos in the left and right arm of the mazes could be watched at the same time and predetermined behavioral events were time stamped as they were observed. If a bird could not be seen in either video, they were presumed to be in the neutral arm of the maze. We measured (i) first arm of the maze visited after a bird entered the maze, (ii) time spent in each arm of the maze, and (iii) activity in each arm of the maze over the 30 min trial. Activity is the sum 
267 of all movements where a bird was no longer in contact with its current perch (e.g., flying or 268 hopping to a new or the original location).

\section{Blood Sampling}

Immediately after being removed from the maze on the trial day, a blood sample was 272 collected from the wing vein. Samples were stored on ice until centrifugation to collect plasma. 273 Plasma was stored at $-20^{\circ} \mathrm{C}$ until assayed for plasma $17 ß$-estradiol and plasma testosterone in 274 females and males, respectively.

\section{Testosterone Assay}

Plasma testosterone was measured using a commercially available enzyme immunoassay kit on a single plate (Enzo Life Sciences, ADI-900-065). Testosterone was extracted from $35 \mu \mathrm{L}$ of plasma using solid phase extraction with C18 columns (100 mg C18 material, Sep-Pak Vac 1cc, Waters, Milford, MA, USA), dried under nitrogen gas at $40^{\circ} \mathrm{C}$, and reconstituted overnight with $250 \mu \mathrm{L}$ assay buffer (Caro et al., 2019). Concentration was adjusted for samples that did not have $35 \mu \mathrm{L}$ of plasma available ( $n=9$ of 22). Reconstituted samples were plated in duplicate (100 $\mu \mathrm{L}$ per well) and concentrations determined using a freely available online five-parameter logistic curve-fitting program (MyAssays Ltd., 2019). Samples below detection limit $(n=1)$ were set at sensitivity of the assay $(5.67 \mathrm{pg} / \mathrm{mL})$. Intra-plate variation was calculated using pooled blue tit plasma from non-breeding individuals. To be certain the pool would produce results near the middle of the curve, $43.6 \mathrm{pg}$ of exogenous testosterone for every $100 \mu \mathrm{L}$ of reconstituted sample was added prior to extraction. The standard was placed in three random locations on the plate and intra-assay variation was calculated at $6.52 \%$.

We validated the assay in blue tits following the methods of (Caro et al., 2019). Briefly, pooled plasma samples were spiked with exogenous testosterone and serially diluted. The assay 
292 was determined to work correctly as percentages of tracer bound (B/B0) from the serial dilutions 293 were parallel to the standard curve (see supplementary material, figure S2).

\section{Estradiol Assay}

Plasma $17 \beta$-estradiol $\left(E_{2}\right)$ was measured using a commercially available double-antibody ${ }^{125} \mathrm{I}_{-} \mathrm{E}_{2}$ radioimmunoassay (DSL-4800, Ultra-sensitive Estradiol RIA, Beckman Coulter, Brea, CA, USA) that was modified by dilution of the tracer and the antibody to increase the sensitivity of the assay, following (Charlier et al., 2010) and (Caro et al., 2019). Like for testosterone, steroids were first extracted from $35 \mu \mathrm{L}$ of plasma using solid phase extraction with C18 columns (100 mg C18 material, Sep-Pak Vac 1cc, Waters, Milford, MA, USA), dried under nitrogen gas at $40^{\circ} \mathrm{C}$, and reconstituted overnight with PBSg (PBS with $0.1 \%$ gelatin) containing $0.7 \%$ ethanol (Caro et al., 2019). Concentration was adjusted for samples that did not have $35 \mu \mathrm{L}$ of plasma available $(n=$ 11 of 20$)$. Resuspended samples were then assayed in duplicate (300 $\mu$ l per tube) and assay tubes were counted on a gamma counter (Automatic Gamma Counter, Perkin Elmer, Waltham, $M A, U S A)$. Concentrations of $E_{2}$ were obtained using a linear regression with the log-transformed concentrations of the standards provided in the assay kit. All samples were run in a single assay, and the intra-assay coefficient of variation, as estimated by assaying one high and one low concentration $\mathrm{E}_{2}$ standard in duplicate, was $5.9 \%$. Assay sensitivity was $0.66 \mathrm{pg} / \mathrm{ml}$. It was defined as the highest point on the standard curve whose standard deviation did not overlap that of the blank standard (Wingfield and Farner, 1975). No sample was found to be below the detection limit. The assay procedure has previously been validated for blue and great tits (Caro et al., 2019).

\section{Statistical Analyses}

All statistical analyses were run in $\mathrm{R}$ version 4.0.3 ( $\mathrm{R}$ Core Team, 2020). As a preliminary analysis we used an exact binomial test to determine that individuals were equally as likely to go to the right side of the maze first ( 26 of 42 ) as they were to go to the left side when they entered 
318 the maze (independently of which side the infested tree was on). Our results showed that birds 319 were not lateralized $(p=0.16)$ and thus we excluded this variable from future analyses. We 320 additionally ran preliminary analyses on behavior during training sessions. Briefly, we found that 321 (i) birds did not become more successful in locating the food reward as the number of trainings 322 increased ( $z=-0.09, p=0.93$, table S1); that (ii) training success was independent of plasma 323 testosterone $(z=-0.96, p=0.34)$ and estradiol $(z=0.14, p=0.89)$; and (iii) the ability to 324 successfully locate the food reward was significantly repeatable within individuals at $0.49(\mathrm{Cl}$ : $3250.21,0.66, p<0.001$, see supplementary materials for more details on these analyses).

After the preliminary analyses, we first ran a simple binomial test that compared the number of birds that chose to visit the infested side when they entered the maze, with the number of birds that first visited the control side. We then used a logistic regression to test the effect of several explanatory variables on first side chosen. We tested whether the first side chosen was influenced by the maze in which an individual was tested (Maze 1 or 2 ), the sex of the birds (M or F), the period the birds were tested (group 1 = habituation, training, and testing from 15 to 21 April, group 2 = habituation, training, and testing from 26 April to 2 May), the order of testing within a group (from 1 to 11 , as a continuous variable), and the number of times no food reward was consumed during training (from 0 to 5, continuous variable, listed as 'Reward Left' in tables 2 and 3). Statistical output for these variables is reported in table 2 and significant values are reported in text. Effect sizes were calculated using package effectsize (Ben-Shachar et al., 2020). We used standardized regression coefficients ( $\beta$ ), which are reported in table 2 along with $95 \%$ confidence intervals.

To determine if time and activity level in each side of the maze differed between infested and control, paired t-tests (one for time, and one for activity) were initially used. To test additional variables that could potentially affect time and activity level in each side of the maze, two linear models were then run (one for each response variable, like above). The response variable for time was calculated as number of seconds spent in the infested arm of the maze minus the 
number of seconds spent in the control arm of the maze. More positive values indicate more time spent in the infested arm, while more negative values indicate more time spent in the control arm.

Similarly, the response variable for activity was calculated as the number of movements made in the infested arm minus the number of movements made in the control arm. More positive values indicate higher activity levels in the infested arm and more negative values indicate higher activity

\section{Results}

Individuals were more likely to visit the side of the maze with the infested tree first (29 of 42) compared to the control tree $(p=0.02)$. On average, birds spent $250.70 \mathrm{~s}$ longer in the side of the maze with the infested tree compared to the side with the control tree $\left(t_{41}=2.13, p=0.04\right.$, figure 1). Birds were also nearly twice as active in the infested side of the maze compared to the control side $\left(t_{41}=3.31, p=0.002\right.$, figure 1$)$. When additional variables are introduced into a more 
369 complex model, they have no influence on first side chosen (all $p>0.1$ ), time (all $p>0.09$ ), or 370 activity (all $p>0.12$, values reported in table 2 ).

Male-restricted analyses showed that birds with higher levels of testosterone spent more 372 time in the infested arm of the maze $\left(F_{1,15}=8.01, p=0.01, R^{2}=0.44\right.$, figure $\left.2 A\right)$. Testosterone was however not related to activity levels $\left(F_{1,15}=3.35, p=0.09, R^{2}=0.43\right.$, table 3$)$. Mean testosterone levels were significantly higher in maze 2 males (386.49 $\pm 122.42 \mathrm{pg} / \mathrm{mL})$ compared to maze 1 males $\left(259.26 \pm 33.2 \mathrm{pg} / \mathrm{mL} ; \mathrm{F}_{1,15}=9.352, p=0.008\right)$, but this pattern was primarily driven by two males in maze 2 with the highest testosterone levels of all 21 individuals (maze 2 mean with highest two males removed: $214.25 \pm 32.60 \mathrm{pg} / \mathrm{mL}$ ). In pre-breeding females, estradiol levels showed no relationship with time $\left(\mathrm{F}_{1,14}=0.01, p=0.94\right.$, figure $\left.2 \mathrm{~B}\right)$ or activity $\left(\mathrm{F}_{1,14}=2.56\right.$, $379 p=0.13$ ). Other variables were also all non-significant (table 3 ).

\section{Discussion}

\section{Blue tits are able to detect minute amounts of plant volatiles}

We found that blue tits are capable of detecting HIPVs emitted by buds of one single small oak infested by young caterpillars. After training, individuals were not only more likely to visit the infested side of the maze first, but they also spent more time and were more active in the infested side of the maze. Our results are supported by other studies showing passerine birds select infested plants over uninfested plants (Amo et al., 2013; Mäntylä et al., 2017, 2008). In addition to the fact that visual cues were excluded in our experiment, emissions from infested buds appear to vary in both composition and quantity of HIPVs when compared to the mature foliage that older caterpillars feed on (Brilli et al., 2009; Röse and Tumlinson, 2004). This is the first study showing birds can detect the trace amounts of HIPVs from trees infested by young caterpillars during early stages of bud development, when caterpillars are not large enough to be considered a food source. 
While our birds were originally naïve, having been in captivity from $10 \mathrm{~d}$ of age, they were 395 trained to associate the presence of food in small dishes with the smell of one infested tree. Our 396 results clearly indicate that the detection of HIPVs from early bud infestation can be a learned 397 behavior. While one study found that naïve great tits do not discriminate between infested and 398 uninfested apple trees, suggesting use of HIPVs from fully developed leaves for locating food is 399 not innate (Amo et al., 2016), new findings in blue tits show that detection of HIPVs from 400 developing buds is innate in this species. When presented with an artificial odor bouquet

Males with higher testosterone levels spent more time in the infested arm

We found that spending more time in the infested arm of the maze compared to the control arm was correlated with higher testosterone levels in males. Although plasma testosterone and time spent in the infested arm were correlated, it is unclear which of the two variables may affect the other. One potential explanation for this relationship is that male blue tits with higher levels of testosterone are more sensitive to cues that could indicate territory that will have higher food abundance. European starlings (Sturnus vulgaris) for example, only exhibit an olfactory response to the odors of a preferred nesting material (De Groof et al., 2010) and a conditioned odor stimulus during the breeding season (Clark and Smeraski, 1990). While artificially increasing plasma testosterone levels during the non-breeding season does not seem to change olfactory sensitivity to preferred nesting material in European starlings (De Groof et al., 2010) or food odor cues in 
420 female goldfish (Carassius auratus) (Ghosal and Sorensen, 2016), the lack of receptors to receive 421 the increased signal might result in non-activation of seasonal changes in olfactory sensitivity. 422 Olfactory processing regions in many other vertebrate species contain gonadotropin releasing 423 hormone $(\mathrm{GnRH})$ and sex steroid receptors (Kawai et al., 2009). Steroid receptor density appears 424 to change with reproductive status in fish (Maruska and Fernald, 2010), while olfactory sensitivity 425 and preference appear to be highest during reproduction in rats (Moffatt, 2003). As the breeding 426 season approaches, males may upregulate receptor density in olfactory processing regions so 427 higher levels of testosterone have a greater influence on olfactory sensitivity during the breeding 428 season. It should also be noted that work in mammals show that exposure to steroid hormones 429 will modulate the integration of chemosensory signals, including olfactory cues. This was 430 particularly well studied in the context of hormonal-dependent onset of maternal behavior in 431 mammals. For example, females begin to show a preference for bedding soiled by pups over 432 clean bedding, around the peripartum period (Kinsley and Bridges, 1990) and this is known to be 433 associated with a general rewiring of the maternal brain (Keller et al., 2019; Lévy and Keller, 434 2009). Steroid-dependent changes in the neural pathways underlying chemosensory integration 435 was also highlighted in copulatory context (Fiber and Swann, 1996; Paredes et al., 1998). 436 Additional work should be performed to define whether sensitivity to HIPVs is modulated at the 437 level of the periphery or the central nervous system, or both.

An alternative explanation for the correlation between testosterone and time spent in the infested arm of the maze is the rapid response of testosterone production to certain stimuli. For example, males of some species can quickly upregulate hormone production in response to malemale competition (Archer, 2006; Mcglothlin et al., 2008; Wingfield and Wada, 1989), presence of a female (Coquelin and Bronson, 1979; Ronay and Hippel, 2010; Stacey, 2003), and even after exposure to a nest box (Gwinner et al., 2002). Male song sparrows showed a significant increase from baseline testosterone levels just $10 \mathrm{~min}$ after the start of a simulated territorial intrusion (Wingfield and Wada, 1989) and the introduction of green vegetation to captive-housed canaries 
446 (Serinus canaria) results in an increase in testosterone (Voigt et al., 2007). Our birds were in the 447 maze and able to interact with the infested trees for up to $30 \mathrm{~min}$, providing ample time for the 448 HIPV cues experienced in the maze to produce measurable differences in testosterone based on 449 time spent near the stimulus (i.e., infested trees).

450 A third potential hypothesis also considers the fact that we trained individuals to associate 451 food with HIPVs and testosterone's apparent role in olfactory sensitivity in rats and mice. For 452 example, in gonadectomized male rats, testosterone injections can restore odor discrimination 453 capabilities and improve task performance (Kunkhyen et al., 2018). However, our results suggest 454 this may not be the case in blue tits. While those individuals with higher levels of testosterone may have spent more time in the infested arm of the maze, testosterone level was not correlated with increased success in locating the food reward during training. Instead, we found that the ability to locate the food reward was repeatable within an individual. Therefore, we think it is unlikely that testosterone played a role in developing a preference for HIPVs, but further work is needed to clarify this relationship.

Another consideration in the role of testosterone in detecting HIPVs is the subsequent reduction in testosterone levels during chick rearing (Hegner and Wingfield, 1987; Hunt et al., 1999), which seems counterintuitive when the ability to locate prey during this period is critical for reproductive success (Visser and Gienapp, 2019). However, fully developed vegetation produces HIPVs in much higher quantities than the early-spring buds we studied here (Brilli et al., 2009; Röse and Tumlinson, 2004), thus, increased olfactory sensitivity may not need to be maintained to successfully forage once HIPVs are emitted in higher quantities in response to herbivory by large caterpillars.

\section{Estradiol is not correlated with behavior in females}

We found no correlation between estradiol and time spent in the infested arm in female blue tits. Estradiol does respond to $\mathrm{GnRH}$ within $30 \mathrm{~min}$ in female great tits (Parus major) and 
dark-eyed juncos (Junco hyemalis) (Caro et al., 2019; Needham et al., 2019), suggesting we would see similar results to testosterone in male blue tits, if perception of a reproductively-relevant stimulus like HIPVs can indeed induce a surge in sex-steroid hormones. Yet female birds control timing of reproduction more closely than males (Caro et al., 2009). While male birds initiate reproductive activity at the beginning of the breeding season and can maintain their status for weeks (Ball and Ketterson, 2008; Caro et al., 2006), increases in plasma estradiol in females is tightly correlated with rapid yolk development (which occurs just prior to egg laying) and decreases to pre-breeding values before the final yolky follicle is ovulated (Williams et al., 2004). Our female blue tits did not lay eggs while housed indoors for this experiment. Similarly, in European starlings, social stimuli via the presence of a male is considered to be important for stimulating final maturation of ovarian follicles (Perfito et al., 2015) and we housed male and female blue tits separately during this experiment. Thus, female blue tits may not produce estradiol in response to herbivore induced HIPVs occurring early in the season because they were not ready to begin egg laying yet. Instead, females may be able to indirectly benefit from increased testosterone in males. Physiological and behavioral changes associated with reproduction are typically observed earlier in males than females (Ball and Ketterson, 2008; Caro et al., 2006). The ability to detect HIPVs may be important for males in locating a high-quality territory.

Testosterone on the other hand, may also be important in detecting environmental cues in females. Interestingly, androgen levels in female European starlings appear to be upregulated prior to rapid yolk development (Williams et al., 2004). For example, testosterone is highest during territory establishment and pre-laying stages in female tree swallows (Tachycineta bicolor); which corresponds with timing of female competition for resources and mates (George and Rosvall, 2018). Testosterone patterns in female blue tits could also upregulate in response to HIPVs and/or influence olfactory sensitivity like in males, but future studies examining the effects of HIPV 
exposure on female reproductive physiology will be needed to unravel the pathway linking HIPV 498 perception to behavioral decisions.

\section{Conclusions}

$501 \quad$ Our study is novel in showing that a passerine bird is able to detect trace HIPVs produced 502 in response to caterpillar infestation of developing buds. As freshly hatched caterpillars are too 503 small and cryptic to be used as food, individuals may use these cues when making other decisions 504 that would improve future reproductive success. Selecting mates based on the quality of the 505 territory they occupy (Alatalo et al., 1986), adjusting clutch size based on habitat quality 506 (Siikamäki, 1995), and timing offspring rearing to occur during peak food availability (Post and 507 Forchhammer, 2008; Reed et al., 2013) are a few possibilities that need to be explored. Our 508 finding that males with higher testosterone levels spend more time with infested trees compared 509 to controls also indicates a possible physiological interaction with HIPVs. Future studies should 510 now focus on how insectivorous vertebrates may use these cues early in the season and how 511 HIPVs affect vertebrate physiology.

\section{Acknowledgements}

514 The authors thank M. Staudt for sharing his expertise in HIPV production; D. Degueldre for 515 building the Y-mazes; M.E. Visser and B. van Lith for providing the winter moth eggs; C. de 516 Francheschi for providing the tortrix eggs; B. Buatois and N. Barthes for assistance setting up the 517 testosterone assay; M.M. Gueguen and M. Simean for assistance with the estradiol assay; S. 518 Bencheikh for watching videos; and S. Ben-Chehida for assisting with tree infestation and bird 519 care during the experiment. 


\section{Funding}

522 This work was supported by the Agence Nationale de la Recherche (awarded to SPC, grant 523 number ANR-15-CE02-0005-01) and a PRESTIGE Postdoctoral Research Fellowship (awarded 524 to JLG, grant number PRESTIGE-2018-2-0007).

525 


\section{References}

Alatalo, R.V., Lundberg, A., Glynn, C., 1986. Female pied flycatchers choose territory quality and not male characteristics. Nature 323, 152-153.

Amo, L., Dicke, M., Visser, M.E., 2016. Are naïve birds attracted to herbivore-induced plant defences? Behaviour 153, 353-366.

Amo, L., Galván, I., Tomás, G., Sanz, J.J., 2008. Predator odour recognition and avoidance in a songbird. Funct. Ecol. 22, 289-293.

Amo, L., Jansen, J.J., van Dam, N.M., Dicke, M., Visser, M.E., 2013. Birds exploit herbivore-induced plant volatiles to locate herbivorous prey. Ecol. Lett. 16, 1348-1355. https://doi.org/10.1111/ele.12177

Andrew, R.J., 1972. Changes in search behaviour in male and female chicks, following different doses of testosterone. Anim. Behav. 20, 741-750. https://doi.org/10.1016/S0003-3472(72)80146-5

Archer, J., 2006. Testosterone and human aggression: an evaluation of the challenge hypothesis. Neurosci. Biobehav. Rev. 30, 319-345.

Ball, G.F., Balthazart, J., 2009. Neuroendocrine regulation of reproductive behavior in birds.

Ball, G.F., Balthazart, J., 2004. Hormonal regulation of brain circuits mediating male sexual behavior in birds. Physiol. Behav., Male Sexual Function 83, 329-346. https://doi.org/10.1016/j.physbeh.2004.08.020

Ball, G.F., Ketterson, E.D., 2008. Sex differences in the response to environmental cues regulating seasonal reproduction in birds. Philos. Trans. R. Soc. Lond. B Biol. Sci. 363, 231-246. https://doi.org/10.1098/rstb.2007.2137

Bates, D., Maechler, M., Bolker, B., Walker, S., 2015. Fitting linear mixed-effects models using Ime4. J. Stat. Softw. 67, 1-48. https://doi.org/10.18637/jss.v067.i01

Ben-Shachar, M., Lüdecke, D., Makowski, D., 2020. effectsize: Estimation of Effect Size Indices and Standardized Parameters. J. Open Source Softw. 5, 2518. https://doi.org/doi: 10.21105/joss.02815

Blondel, J., Dias, P.C., Perret, P., Maistre, M., Lambrechts, M.M., 1999. Selection-based biodiversity at a small spatial scale in a low-dispersing insular bird. Science 285, 1399-1402.

Bonadonna, F., Caro, S.P., Jouventin, P., Nevitt, G.A., 2006. Evidence that blue petrel, Halobaena caerulea, fledglings can detect and orient to dimethyl sulfide. J. Exp. Biol. 209, 2165-2169. https://doi.org/10.1242/jeb.02252

Bonadonna, F., Gagliardo, A., 2021. Not only pigeons: avian olfactory navigation studied by satellite telemetry. Ethol. Ecol. Evol. 33. https://doi.org/10.1080/03949370.2021.1871967

Bonadonna, F., Nevitt, G.A., 2004. Partner-Specific Odor Recognition in an Antarctic Seabird. Science 306, 835-835. https://doi.org/10.1126/science.1103001

Bonadonna, F., Sanz-Aguilar, A., 2012. Kin recognition and inbreeding avoidance in wild birds: the first evidence for individual kin-related odour recognition. Anim. Behav. 84, 509-513.

Brilli, F., Ciccioli, P., Frattoni, M., Prestininzi, M., Spanedda, A.F., Loreto, F., 2009. Constitutive and herbivore-induced monoterpenes emitted by Populus\$times\$ euroamericana leaves are key volatiles that orient Chrysomela populi beetles. Plant Cell Environ. 32, 542-552.

Caro, S.P., Balthazart, J., 2010. Pheromones in birds: myth or reality? J. Comp. Physiol. A 196, 751-766.

Caro, S.P., Charmantier, A., Lambrechts, M.M., Blondel, J., Balthazart, J., Williams, T.D., 2009. Local adaptation of timing of reproduction: females are in the driver's seat. Funct. Ecol. 23, 172-179.

Caro, S.P., Cornil, C.A., van Oers, K., Visser, M.E., 2019. Personality and gonadal development as sources of individual variation in response to $\mathrm{GnRH}$ challenge in female great tits. Proc. R. Soc. B Biol. Sci. 286, 20190142. https://doi.org/10.1098/rspb.2019.0142 
Caro, S.P., Lambrechts, M.M., Chastel, O., Sharp, P.J., Thomas, D.W., Balthazart, J., 2006. Simultaneous pituitary-gonadal recrudescence in two Corsican populations of male blue tits with asynchronous breeding dates. Horm. Behav. 50, 347-360. https://doi.org/10.1016/j.yhbeh.2006.03.001

Charlier, T.D., Po, K.W., Newman, A.E., Shah, A.H., Saldanha, C.J., Soma, K.K., 2010. 17ß-Estradiol levels in male zebra finch brain: combining Palkovits punch and an ultrasensitive radioimmunoassay. Gen. Comp. Endocrinol. 167, 18-26.

Clark, L., Mason, J.R., 1987. Olfactory discrimination of plant volatiles by the European starling. Anim. Behav. 35, 227-235. https://doi.org/10.1016/S0003-3472(87)80228-2

Clark, L., Smeraski, C.A., 1990. Seasonal shifts in odor acuity by starlings. J. Exp. Zool. 255, 22-29.

Coquelin, A., Bronson, F.H., 1979. Release of luteinizing hormone in male mice during exposure to females: habituation of the response. Science 206, 1099-1101.

Cunningham, G.B., Van Buskirk, R.W., Bonadonna, F., Weimerskirch, H., Nevitt, G.A., 2003. A comparison of the olfactory abilities of three species of procellariiform chicks. J. Exp. Biol. 206, 1615-1620.

Daisley, J.N., Bromundt, V., Möstl, E., Kotrschal, K., 2005. Enhanced yolk testosterone influences behavioral phenotype independent of sex in Japanese quail chicks Coturnix japonica. Horm. Behav. 47, 185-194.

De Groof, G., Gwinner, H., Steiger, S., Kempenaers, B., Van der Linden, A., 2010. Neural correlates of behavioural olfactory sensitivity changes seasonally in European starlings. PLoS One 5, e14337.

Du Merle, P., Mazet, R., 1983. Stades phénologiques et infestation par Tortrix viridana L.(Lep., Tortricidae) des bourgeons du chêne pubescent et du chêne vert. Acta Oecologica 4, 47-53.

Fiber, J.M., Swann, J.M., 1996. Testosterone differentially influences sex-specific pheromone-stimulated Fos expression in limbic regions of Syrian hamsters. Horm. Behav. 30, 455-473.

Fleissner, G., Fleissner, G., 2002. Perception of Natural Zeitgeber Signals, in: Kumar, V. (Ed.), Biological Rhythms. Springer Berlin Heidelberg, pp. 83-93. https://doi.org/10.1007/978-3-662-06085-8_8

Friard, O., Gamba, M., 2016. BORIS: a free, versatile open-source event-logging software for video/audio coding and live observations. Methods Ecol. Evol. 7, 1325-1330. https://doi.org/10.1111/2041210X.12584

Gagliardo, A., Bried, J., Lambardi, P., Luschi, P., Wikelski, M., Bonadonna, F., 2013. Olfactory oceanic navigation in an Atlantic seabird. J Exp Biol 216, 2798-2805.

George, E.M., Rosvall, K.A., 2018. Testosterone production and social environment vary with breeding stage in a competitive female songbird. Horm. Behav. 103, 28-35.

Ghosal, R., Sorensen, P.W., 2016. Male-typical courtship, spawning behavior, and olfactory sensitivity are induced to different extents by androgens in the goldfish suggesting they are controlled by different neuroendocrine mechanisms. Gen. Comp. Endocrinol. 232, 160-173.

Girling, R.D., Stewart-Jones, A., Dherbecourt, J., Staley, J.T., Wright, D.J., Poppy, G.M., 2011. Parasitoids select plants more heavily infested with their caterpillar hosts: a new approach to aid interpretation of plant headspace volatiles. Proc. R. Soc. B Biol. Sci. 278, 2646-2653. https://doi.org/10.1098/rspb.2010.2725

Gols, R., Roosjen, M., Dijkman, H., Dicke, M., 2003. Induction of Direct and Indirect Plant Responses by Jasmonic Acid, Low Spider Mite Densities, or a Combination of Jasmonic Acid Treatment and Spider Mite Infestation. J. Chem. Ecol. 29, 2651-2666. https://doi.org/10.1023/B:JOEC.0000008010.40606.b0

Gwinner, H., Van't Hof, T., Zeman, M., 2002. Hormonal and behavioral responses of starlings during a confrontation with males or females at nest boxes during the reproductive season. Horm. Behav. 42, 21-31.

Hegner, R.E., Wingfield, J.C., 1987. Effects of experimental manipulation of testosterone levels on parental investment and breeding success in male house sparrows. The Auk 104, 462-469. 
Horie, S., Yamaki, A., Takami, S., 2017. Presence of Sex Steroid-Metabolizing Enzymes in the Olfactory Mucosa of Rats. Anat. Rec. 300, 402-414.

Hunt, K.E., Hahn, T.P., Wingfield, J.C., 1999. Endocrine influences on parental care during a short breeding season: testosterone and male parental care in Lapland longspurs (Calcarius lapponicus). Behav. Ecol. Sociobiol. 45, 360-369.

Hussell, D.J.T., Quinney, T.E., 1987. Food abundance and clutch size of Tree Swallows Tachycineta bicolor. Ibis 129, 243-258.

Kawai, T., Oka, Y., Eisthen, H., 2009. The role of the terminal nerve and GnRH in olfactory system neuromodulation. Zoolog. Sci. 26, 669-680.

Keller, M., Vandenberg, L.N., Charlier, T.D., 2019. The parental brain and behavior: A target for endocrine disruption. Front. Neuroendocrinol. 54, 100765.

Kesselmeier, J., Staudt, M., 1999. Biogenic volatile organic compounds (VOC): an overview on emission, physiology and ecology. J. Atmospheric Chem. 33, 23-88.

Kessler, A., Baldwin, I.T., 2001. Defensive Function of Herbivore-Induced Plant Volatile Emissions in Nature. Science 291, 2141-2144. https://doi.org/10.1126/science.291.5511.2141

Kinsley, C.H., Bridges, R.S., 1990. Morphine treatment and reproductive condition alter olfactory preferences for pup and adult male odors in female rats. Dev. Psychobiol. J. Int. Soc. Dev. Psychobiol. 23, 331-347.

Krause, E.T., Krüger, O., Kohlmeier, P., Caspers, B.A., 2012. Olfactory kin recognition in a songbird. Biol. Lett. 8, 327-329.

Kunkhyen, T., Perez, E., Bass, M., Coyne, A., Baum, M.J., Cherry, J.A., 2018. Gonadal hormones, but not sex, affect the acquisition and maintenance of a Go/No-Go odor discrimination task in mice. Horm. Behav. 100, 12-19.

Lack, D.L., 1968. Ecological adaptations for breeding in birds.

Lévy, F., Keller, M., 2009. Olfactory mediation of maternal behavior in selected mammalian species. Behav. Brain Res. 200, 336-345.

Lupo, C., Lodi, L., Canonaco, M., Valenti, A., Dessì-Fulgheri, F., 1986. Testosterone metabolism in the olfactory epithelium of intact and castrated male rats. Neurosci. Lett. 69, 259-262. https://doi.org/10.1016/0304-3940(86)90490-8

Mäntylä, E., Alessio, G.A., Blande, J.D., Heijari, J., Holopainen, J.K., Laaksonen, T., Piirtola, P., Klemola, T., 2008. From plants to birds: higher avian predation rates in trees responding to insect herbivory. PLoS One 3, e2832.

Mäntylä, E., Kleier, S., Kipper, S., Hilker, M., 2017. The attraction of insectivorous tit species to herbivore-damaged Scots pines. J. Ornithol. 158, 479-491.

Marciniak, B., Nadolski, J., Nowakowska, M., Loga, B., Bańbura, J., 2007. Habitat and annual variation in arthropod abundance affects Blue Tit Cyanistes caeruleus reproduction. Acta Ornithol. 42, 5362.

Maruska, K.P., Fernald, R.D., 2010. Reproductive Status Regulates Expression of Sex Steroid and GnRH Receptors in the Olfactory Bulb. Behav. Brain Res. 213, 208-217. https://doi.org/10.1016/j.bbr.2010.04.058

Mcglothlin, J.W., Jawor, J.M., Greives, T.J., Casto, J.M., Phillips, J.L., Ketterson, E.D., 2008. Hormones and honest signals: males with larger ornaments elevate testosterone more when challenged. J. Evol. Biol. 21, 39-48. https://doi.org/10.1111/j.1420-9101.2007.01471.x

Mennerat, A., Bonadonna, F., Perret, P., Lambrechts, M.M., 2005. Olfactory conditioning experiments in a food-searching passerine bird in semi-natural conditions. Behav. Processes 70, 264-270. https://doi.org/10.1016/j.beproc.2005.07.005

Miller, S.L., Maner, J.K., 2010. Scent of a Woman: Men's Testosterone Responses to Olfactory Ovulation Cues. Psychol. Sci. 21, 276-283. https://doi.org/10.1177/0956797609357733 
Moffatt, C.A., 2003. Steroid hormone modulation of olfactory processing in the context of socio-sexual behaviors in rodents and humans. Brain Res. Rev. 43, 192-206.

Mrazova, A., Sam, K., Amo, L., 2019. What do we know about birds' use of plant volatile cues in tritrophic interactions? Curr. Opin. Insect Sci.

MyAssays Ltd., 2019. Five Parameter Logistic Curve online data analysis tool. MyAssays Ltd.

Naef-Daenzer, B., Keller, L.F., 1999. The foraging performance of great and blue tits (Parus major and P. caeruleus) in relation to caterpillar development, and its consequences for nestling growth and fledging weight. J. Anim. Ecol. 68, 708-718. https://doi.org/10.1046/j.1365-2656.1999.00318.x

Needham, K.B., Bergeon Burns, C.M., Graham, J.L., Bauer, C.M., Kittilson, J.D., Ketterson, E.D., Hahn, T.P., Greives, T.J., 2019. Changes in processes downstream of the hypothalamus are associated with seasonal follicle development in a songbird, the dark-eyed junco (Junco hyemalis). Gen. Comp. Endocrinol. 270, 103-112. https://doi.org/10.1016/j.ygcen.2018.10.012

Németh, Z., Adams, R.H., Ramenofsky, M., 2015. Androgens Increase Persistence But Do Not Affect Neophobia in a Problem-Solving Context in a Songbird. Ethology 121, 428-433.

Nikonov, A.A., Butler, J.M., Field, K.E., Caprio, J., Maruska, K.P., 2017. Reproductive and metabolic state differences in olfactory responses to amino acids in a mouth brooding African cichlid fish. J. Exp. Biol. 220, 2980-2992.

Nyström, K.G.K., 1997. Food density, song rate, and body condition in territory-establishing willow warblers (Phylloscopus trochilus). Can. J. Zool. 75, 47-58. https://doi.org/10.1139/z97-006

Paredes, R.G., Lopez, M.E., Baum, M.J., 1998. Testosterone augments neuronal Fos responses to estrous odors throughout the vomeronasal projection pathway of gonadectomized male and female rats. Horm. Behav. 33, 48-57.

Perfito, N., Guardado, D., Williams, T.D., Bentley, G.E., 2015. Social cues regulate reciprocal switching of hypothalamic Dio2/Dio3 and the transition into final follicle maturation in European starlings (Sturnus vulgaris). Endocrinology 156, 694-706.

Petit, C., Hossaert-McKey, M., Perret, P., Blondel, J., Lambrechts, M.M., 2002. Blue tits use selected plants and olfaction to maintain an aromatic environment for nestlings. Ecol. Lett. 5, 585-589. https://doi.org/10.1046/j.1461-0248.2002.00361.x

Petrulis, A., 2013. Chemosignals, hormones and mammalian reproduction. Horm. Behav. 63, 723-741. https://doi.org/10.1016/j.yhbeh.2013.03.011

Post, E., Forchhammer, M.C., 2008. Climate change reduces reproductive success of an Arctic herbivore through trophic mismatch. Philos. Trans. R. Soc. Lond. B Biol. Sci. 363, 2367-2373. https://doi.org/10.1098/rstb.2007.2207

R Core Team, 2020. R: A language and environment for statistical computing. R Foundation for Statistical Computing, Vienna, Austria. URL https://www.R-project.org.

Reed, T.E., Jenouvrier, S., Visser, M.E., 2013. Phenological mismatch strongly affects individual fitness but not population demography in a woodland passerine. J. Anim. Ecol. 82, 131-144.

Ronay, R., Hippel, W. von, 2010. The presence of an attractive woman elevates testosterone and physical risk taking in young men. Soc. Psychol. Personal. Sci. 1, 57-64.

Rondoni, G., lelo, F., Ricci, C., Conti, E., 2017. Behavioural and physiological responses to prey-related cues reflect higher competitiveness of invasive vs. native ladybirds. Sci. Rep. 7, 1-9.

Röse, U.S., Tumlinson, J.H., 2004. Volatiles released from cotton plants in response to Helicoverpa zea feeding damage on cotton flower buds. Planta 218, 824-832.

Roth II, T.C., Cox, J.G., Lima, S.L., 2008. Can foraging birds assess predation risk by scent? Anim. Behav. 76, 2021-2027.

Siikamäki, P., 1995. Habitat Quality and Reproductive Traits in the Pied Flycatcher: An Experiment. Ecology 76, 308-312. https://doi.org/10.2307/1940652 
Stacey, N., 2003. Hormones, pheromones and reproductive behavior. Fish Physiol. Biochem. 28, 229235.

Stoffel, M., Nakagawa, S., Schielzeth, H., 2017. rptR: repeatability estimation and variance decomposition by generalized linear mixed-effects models. Methods Ecol. Evol. 8, 1639-1644.

Turlings, T.C.J., Benrey, B., 1998. Effects of plant metabolites on the behavior and development of parasitic wasps. Écoscience 5, 321-333. https://doi.org/10.1080/11956860.1998.11682472

Van Poecke, R.M., Posthumus, M.A., Dicke, M., 2001. Herbivore-induced volatile production by Arabidopsis thaliana leads to attraction of the parasitoid Cotesia rubecula: chemical, behavioral, and gene-expression analysis. J. Chem. Ecol. 27, 1911-1928.

Visser, M.E., Gienapp, P., 2019. Evolutionary and demographic consequences of phenological mismatches. Nat. Ecol. Evol. 3, 879-885.

Voigt, C., Goymann, W., Leitner, S., 2007. Green matters! Growing vegetation stimulates breeding under short-day conditions in wild canaries (Serinus canaria). J. Biol. Rhythms 22, 554-557.

Whittaker, D.J., Richmond, K.M., Miller, A.K., Kiley, R., Bergeon Burns, C., Atwell, J.W., Ketterson, E.D., 2011. Intraspecific preen oil odor preferences in dark-eyed juncos (Junco hyemalis). Behav. Ecol. 22, 1256-1263. https://doi.org/10.1093/beheco/arr122

Wickham, H., 2016. ggplot2:Elegant Graphics for Data Analysis. Springer-Verlag New York, New York, NY, USA.

Williams, T.D., Kitaysky, A.S., Vézina, F., 2004. Individual variation in plasma estradiol-17ß and androgen levels during egg formation in the European starling Sturnus vulgaris: implications for regulation of yolk steroids. Gen. Comp. Endocrinol. 136, 346-352. https://doi.org/10.1016/j.ygcen.2004.01.010

Wingfield, J.C., 1984. Androgens and mating systems: testosterone-induced polygyny in normally monogamous birds. The Auk 101, 665-671.

Wingfield, J.C., Ball, G.F., Jr., A.M.D., Hegner, R.E., Ramenofsky, M., 1987. Testosterone and Aggression in Birds. Am. Sci. 75, 602-608.

Wingfield, J.C., Farner, D.S., 1975. The determination of five steroids in avian plasma by radioimmunoassay and competitive protein-binding. Steroids 26, 311-327.

Wingfield, J.C., Wada, M., 1989. Changes in plasma levels of testosterone during male-male interactions in the song sparrow, Melospiza melodia: time course and specificity of response. J. Comp. Physiol. A 166, 189-194. 


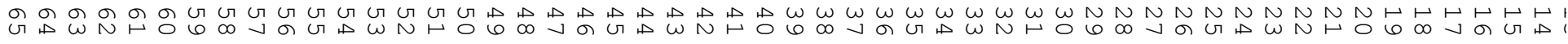

जे

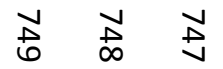

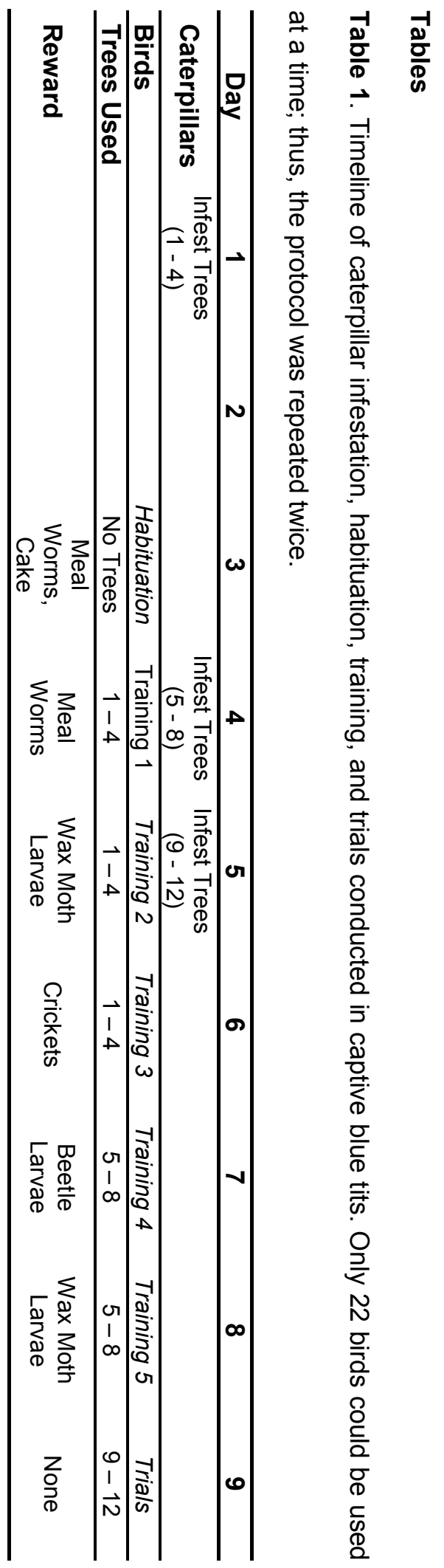




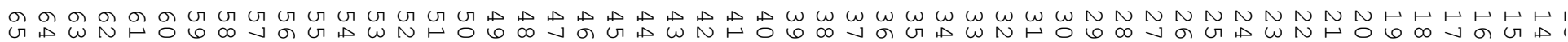
ऊे के

जั जั

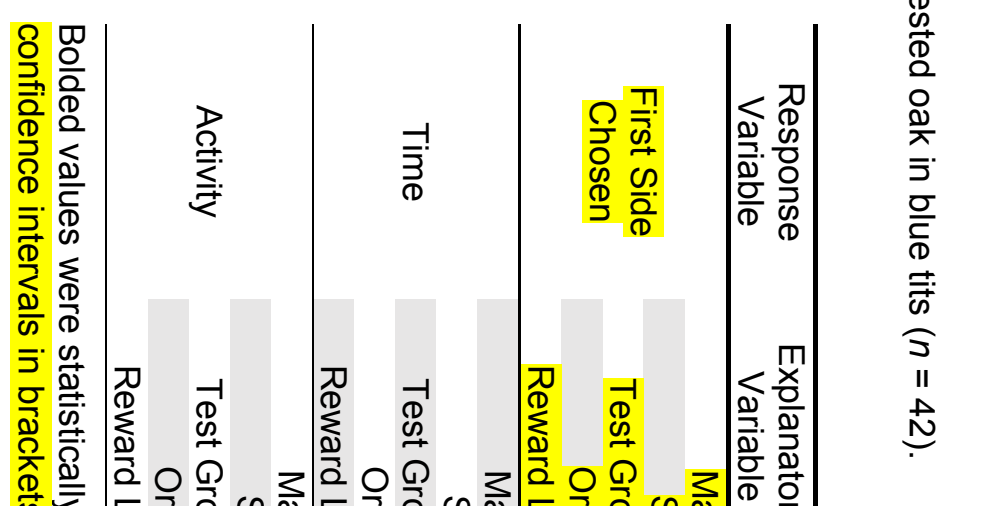

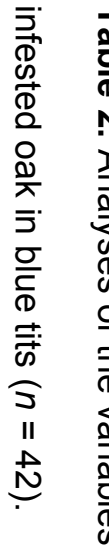

D

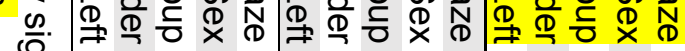

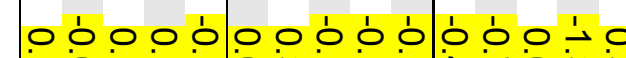

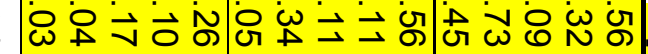

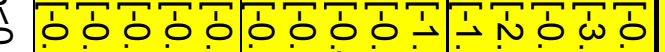

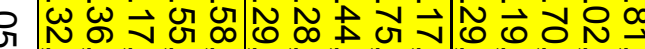

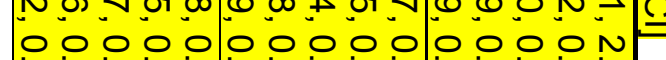

$\dot{\omega}_{\infty}$ 워

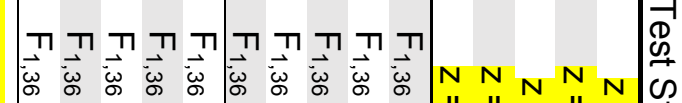

II II II II II II II II II II ||

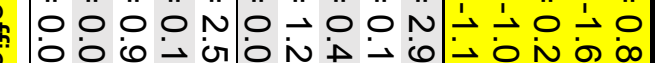
N 


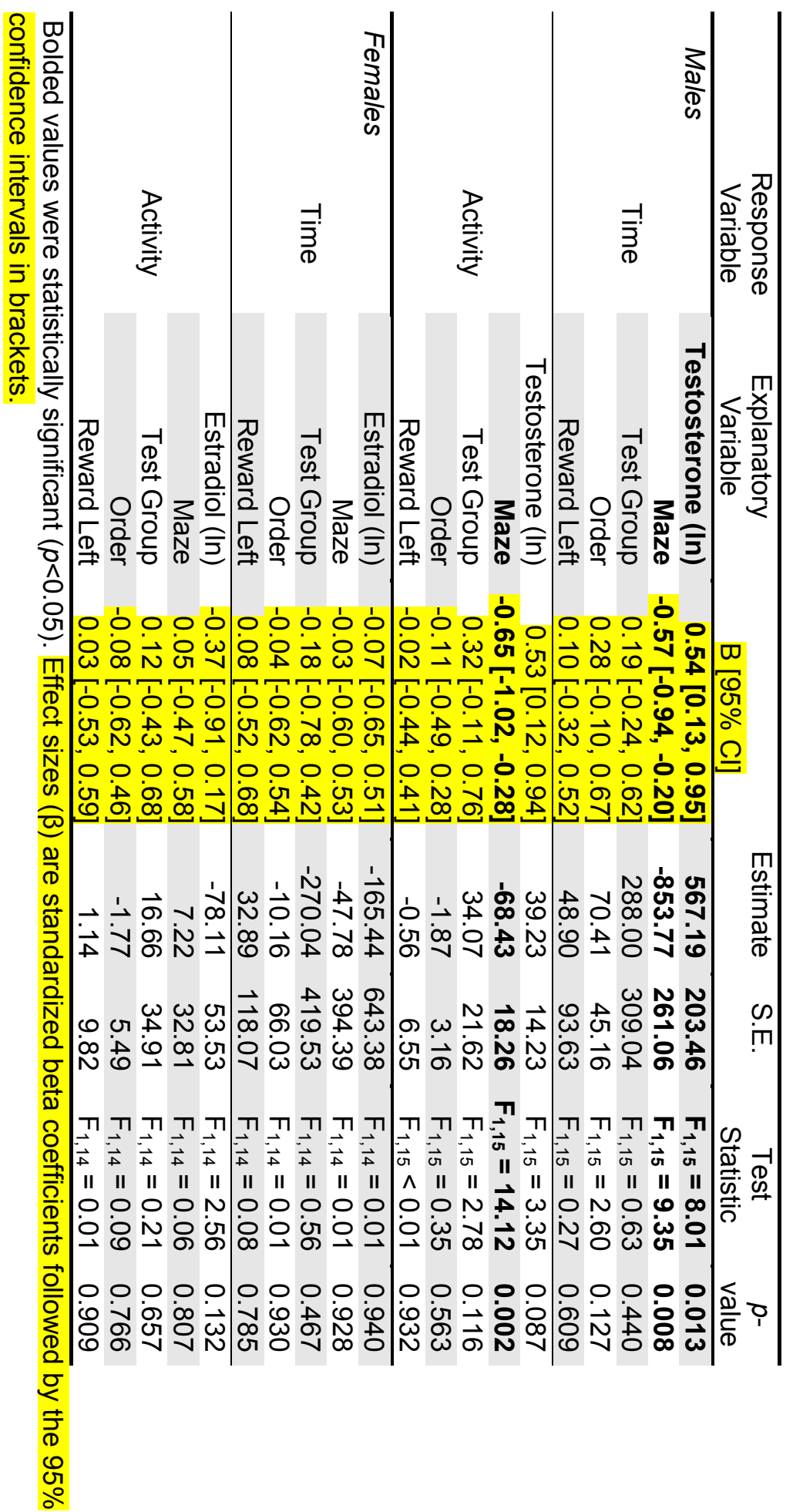




\section{Figures}

771 Figure 1. Blue tits detect herbivore-induced plant volatiles (HIPV) emitted by the buds of one 772 single, small oak. On average, individuals spent 250.7 seconds longer in the infested arm of the 773 maze than the control arm and were significantly more active in the infested arm of the maze 774 compared to the control arm. Activity is the sum of all movements where a bird was no longer in 775 contact with its current perch (e.g., flying or hopping to a new or the original location). Circles 776 represent individual data points while squares represent mean of all individuals \pm SEM.

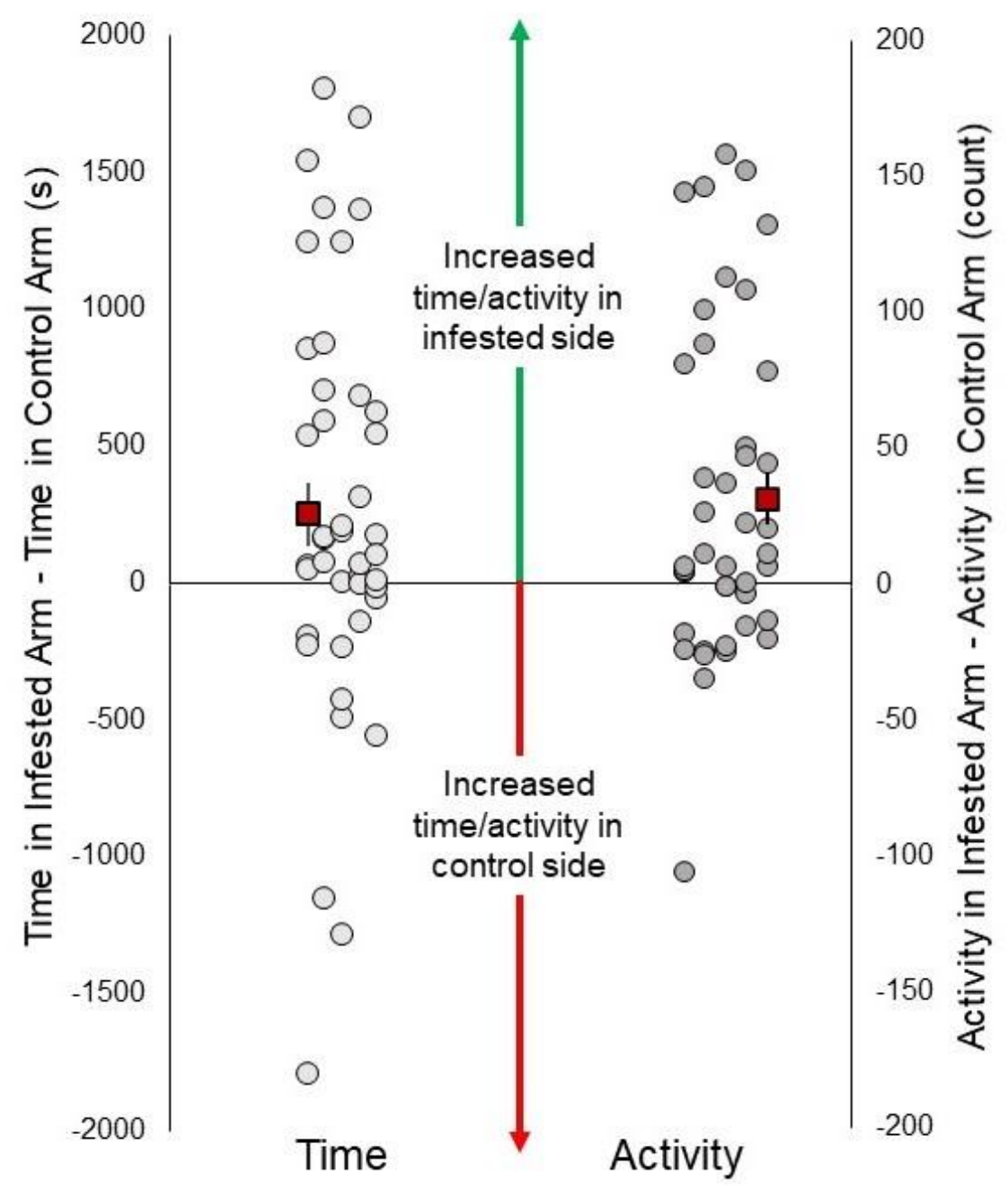


778 Figure 2. Testosterone correlates with HIPV detection. (A) Males with higher levels of

779 testosterone spent significantly more time in the infested arm of the maze compared to the

780 control arm of the maze, (B) but this was not the case for the relationship with estradiol in

781 females.
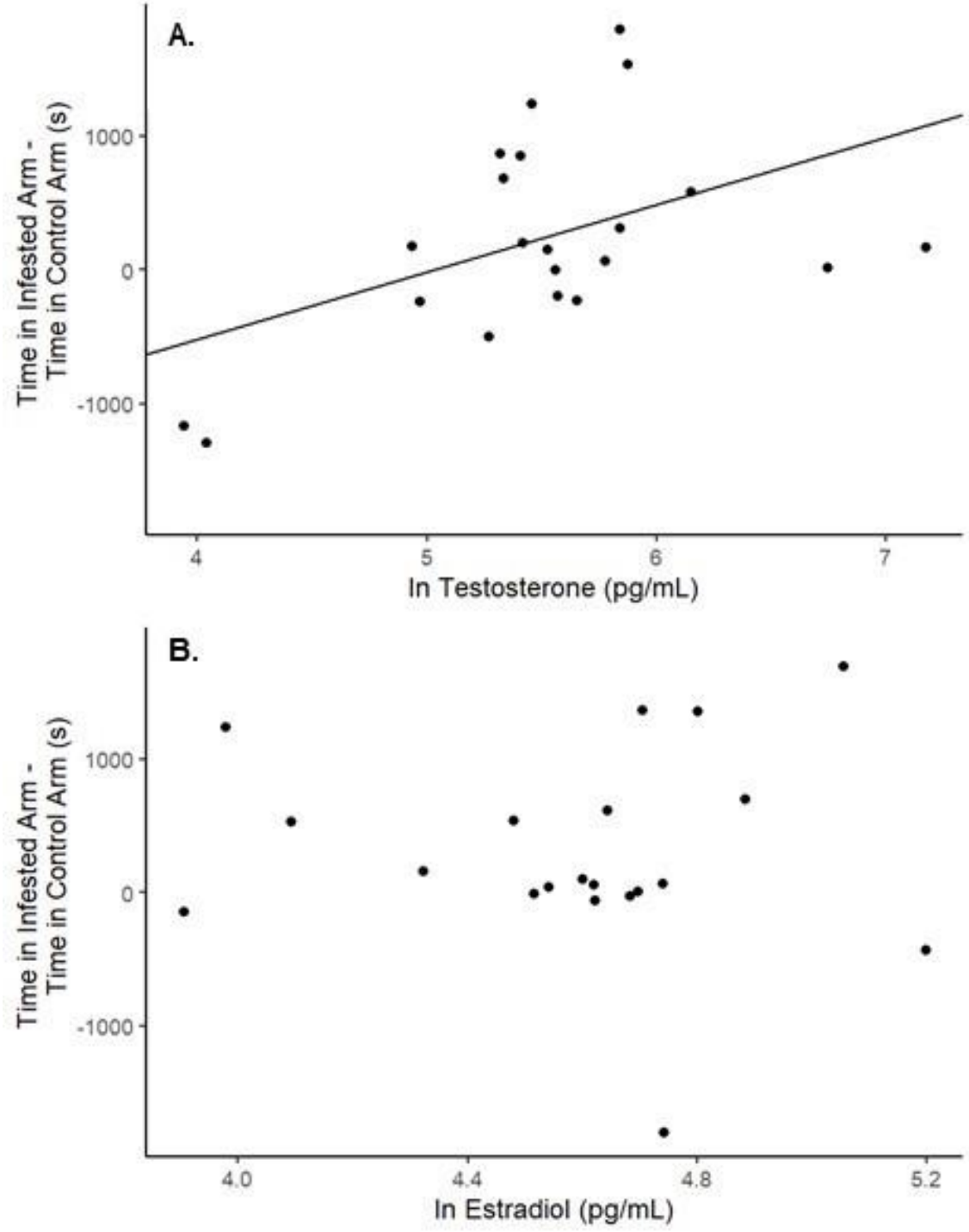


\section{Supplementary Material \\ 784 Behavioral analyses during training}

We ran preliminary analyses on bird behavior related with successfully locating food 786 during training. To test whether individuals became more successful at finding the food reward 787 during trainings using a generalized linear mixed-model with binomial distribution in package Ime4 788 (Bates et al., 2015). The response variable was a repeated measure coded as 1 (consumed food 789 reward) or 0 (did not consume food reward) for each of the 5 training sessions. Our fixed factor 790 of interest in the model was the training session $(1-5)$. Individuals were tested in two mazes, 791 during two different time periods, thus, to determine if these variables affected the results, the 792 maze an individual was tested in (Maze 1 or 2) and the test group (group 1 = habituation, training, 793 and testing from 15 to 21 April, group 2 = habituation, training, and testing from 26 April to 2 May) 794 were both included in the model. Testing order is included as a measure of when an individual 795 was tested during the day. Those listed as 1 were the first to be tested on that day and those 796 listed as 10 or 11 were last to be tested that day. Sex (M or F) was also included. Statistical output 797 for these variables is reported in table S1 and significant values are reported in the main text. 798 Given the evidence that testosterone can influence olfactory discrimination in rats and mice 799 (Kunkhyen et al., 2018), we also decided to run 2 additional models comparing testosterone in 800 males and estradiol in females to training success. Furthermore, we calculated the repeatability 801 (logit link-scale approximation) of consuming the food reward across the five trainings using the 802 package rptR (Stoffel et al., 2017). 


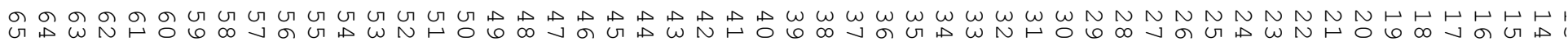

号 $\stackrel{\infty}{\sim}$

$\stackrel{\infty}{\$} \quad \stackrel{\infty}{\omega}$

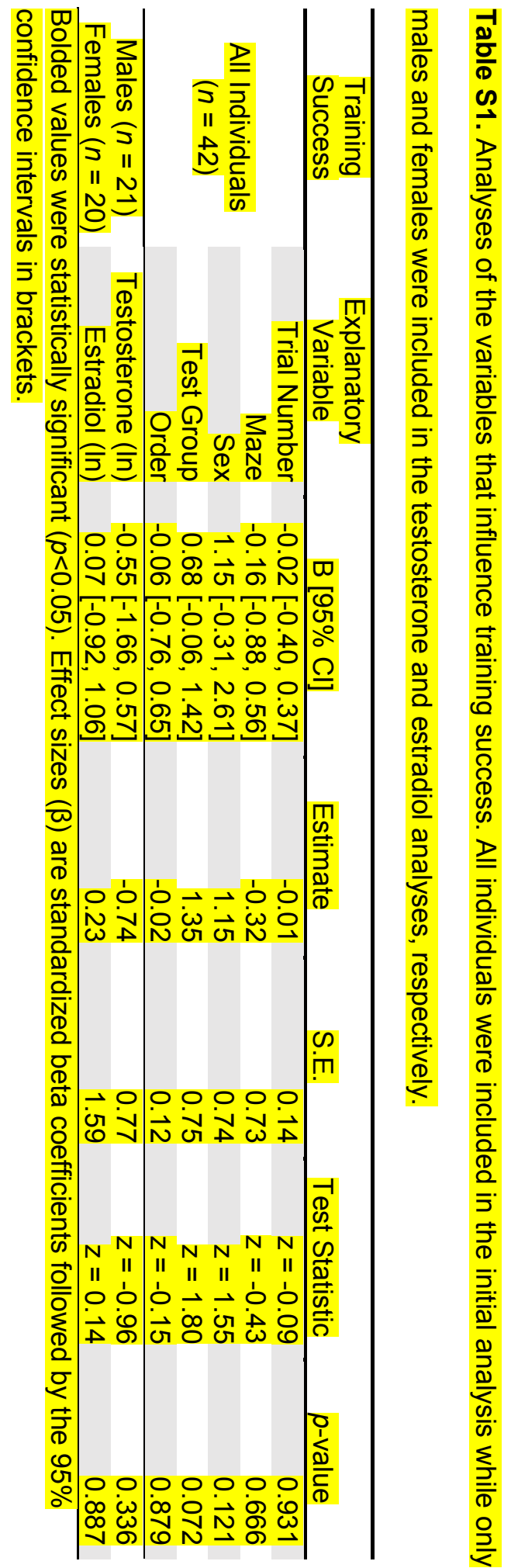


807 Figure S1. Diagram of the Y-mazes used in the behavioral experiment. To test the ability of 808 insectivorous songbirds to detect caterpillar infestation of oak buds by smell, a Y-maze was set 809 up so birds entered from a small box in the neutral arm. Two GoPro cameras were mounted on 810 a center perch to film activity in each of the active arms. An infested oak tree was on one side of 811 the maze and an uninfested tree on the other. Both were visually isolated from the bird to 812 obscure any visual changes resulting from infestation, but small fans were in place to help direct 813 any odors toward the center of the maze. Each trial lasted 30 minutes.

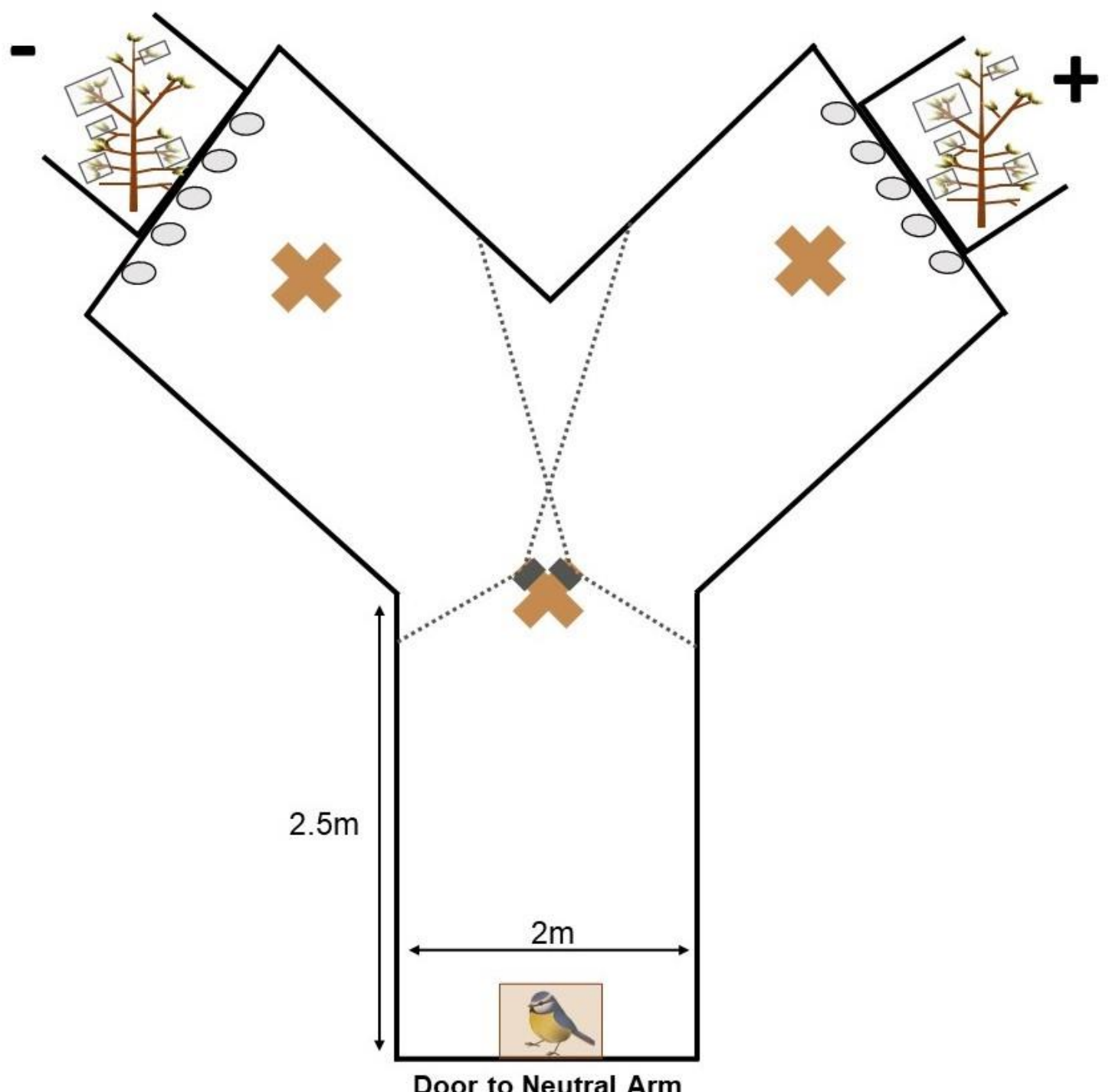

Door to Neutral Arm 
815 Figure S2. Testosterone assay validation for blue tit plasma. To validate the assay in blue tits, 2 816 plasma pools were created from samples collected from blue tits in January 2018. The first pool 817 was spiked with $19.7 \mathrm{pg}$ of exogenous testosterone per well (low spike) and the second pool was 818 spiked with $39.5 \mathrm{pg}$ of exogenous testosterone per well (high spike) to ensure the entire serial 819 dilution of the pooled samples would fall on the curve. Each plasma pool was then serially diluted 820 to create a 5-point curve. During validation, testosterone was extracted from $35 \mu \mathrm{L}$ of plasma 821 using solid phase extraction with C18 columns (100 mg C18 material, Sep-Pak Vac 1cc, Waters, 822 Milford, MA, USA), dried under nitrogen gas at $40^{\circ} \mathrm{C}$, and reconstituted overnight with $250 \mu \mathrm{L}$ 823 assay buffer (Caro et al., 2019). Recovery after extraction was $57.3 \%$ and $64.4 \%$ for low and high 824 spiked curves, respectively.

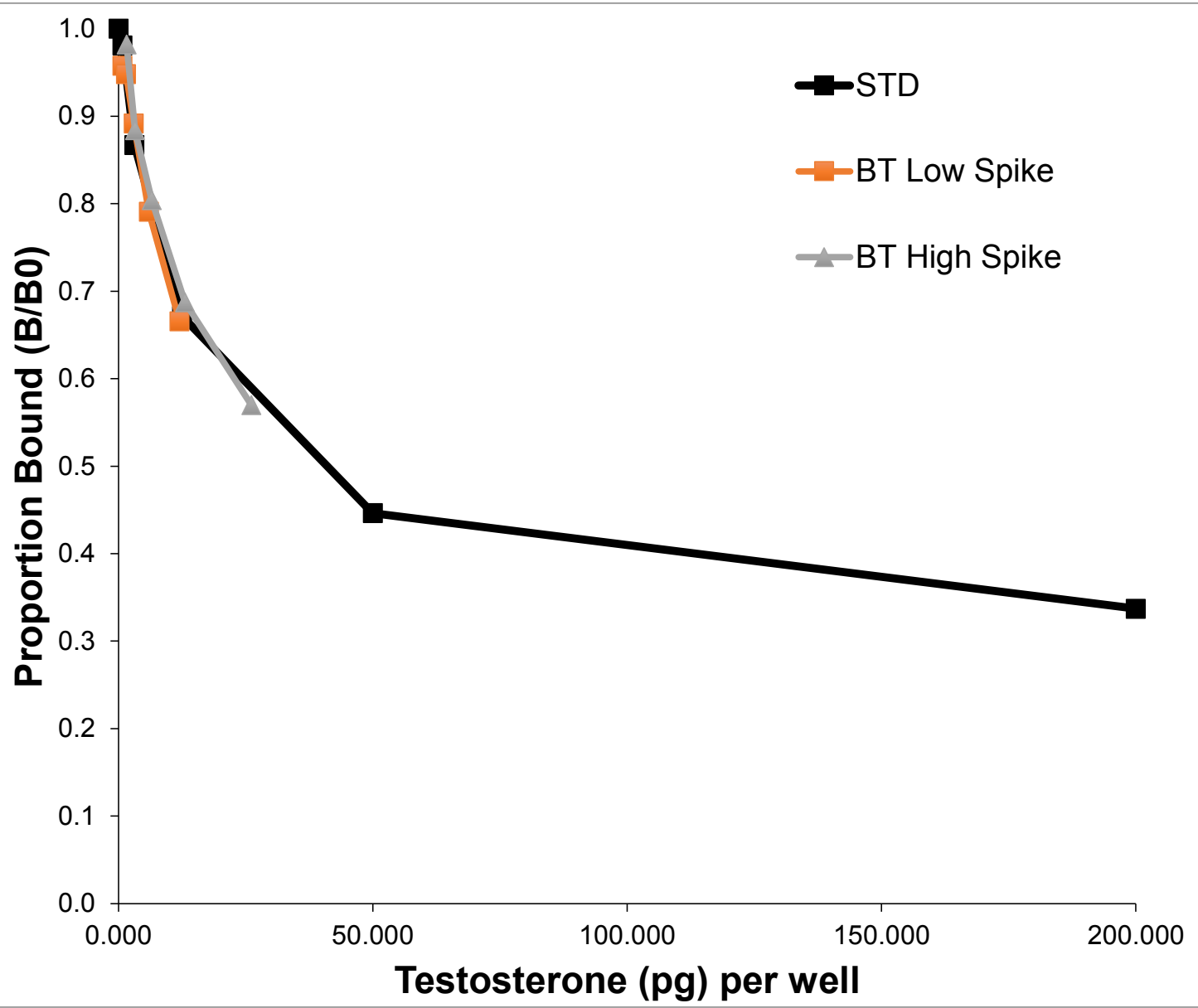

